\title{
ADUBAÇÃO SUPERFICIAL COM FÓSFORO E POTÁSSIO PARA A SOJA EM DIFERENTES ÉPOCAS EM PRÉ-SEMEADURA NA INSTALAÇÃO DO SISTEMA DE PLANTIO DIRETO
}

\author{
SUPERFICIAL FERTILIZATION WITH PHOSPHORUS AND POTASSIUM IN THE \\ SOY CROP (GLYCINE MAX (L.) MERRILL) AT DIFFERENT SOWING TIMES IN \\ PRE SOWING UNDER A NO-TILLAGE SYSTEM INPLANTATION
}

\author{
Regina Maria Quintão LANA ${ }^{1}$ \\ Carlos Eduardo VILELA FILHO² \\ Luiz Antônio ZANÃO JÚNIOR ${ }^{3}$ \\ Hamilton Seron PEREIRA ${ }^{4}$ \\ Ângela Maria Quintão LANA ${ }^{5}$
}

\begin{abstract}
RESUMO
O experimento foi conduzido na fazenda Capim Branco da Universidade Federal de Uberlândia, no município de UberlândiaMG, no período de junho de 1999 a abril de 2002. O objetivo desse trabalho foi avaliar a aplicação antecipada do fertilizante fosfatado e potássico, a lanço, em pré-semeadura, sob sistema de plantio direto, na cultura da soja, cv. MG/BR-46 Conquista, durante três anos agrícolas. O delineamento experimental foi o de blocos ao acaso com cinco tratamentos e cinco repetições. As adubações (100 kg. ha-1 de $\mathrm{P}_{2} \mathrm{O}_{5}$ e $100 \mathrm{~kg}$.ha-1 $\mathrm{de} \mathrm{K}_{2}$ ) foram aplicadas a lanço, superficiais, antecipadas, realizadas todos os anos nos meses de julho, agosto, setembro, outubro e novembro (juntamente com a semeadura). As variáveis avaliadas foram: produtividade, teores de $\mathrm{P}$ e $\mathrm{K}$ foliar e do solo, altura da primeira vagem em relação ao solo e peso de cem sementes. A adubação com fósforo e potássio na instalação do sistema de plantio direto, a lanço, antecipada até cinco meses antes da semeadura, não influenciou o rendimento de grãos da soja, os teores de $\mathrm{P}$ e $\mathrm{K}$ nas folhas, o peso de cem sementes e a altura da primeira vagem em relação ao solo. Com os cultivos sucessivos, observou-se aumento significativo de todas as características avaliadas e acúmulo de $\mathrm{P}$ e $\mathrm{K}$ no solo.
\end{abstract}

Palavras-chave: Glycine max, multifosfato magnesiano, efeito residual, fertilizante.

\begin{abstract}
The experiment was carried out at the Capim Branco Farm, which belongs to the Federal University of Uberlândia, city of Uberlandia, Minas Gerais state, in the period from June 1999 through April 2002. It had as objective to evaluate the anticipated application of the fosfated and potassic fertilizer, the throwing, in presowing, under no-tillage, in the soy crop, cv. MG/BR-46 Conquista, during trhee cropping seasons. The used delineation was randomized blocks with five treatments (application times) and five replications. The fertilizations ( $100 \mathrm{~kg} \cdot$ ha- ${ }^{-1}$ of $\mathrm{P}_{2} \mathrm{O}_{5}$ and $100 \mathrm{~kg} \cdot$ ha $^{-1}$ of $\left.\mathrm{K}_{2} 0\right)$ had been applied the throw, superficial, anticipated, carried through every year in the months of July, August, September, October and November (together with the sowing). The evaluated variables had been: productivity, ratio of $\mathrm{P}$ and $\mathrm{K}$ in the soil and leaves, first pod height in relation to the soil and weight of 100 seeds. The fertilization with match and potassium in the installation of the no-tillage system, the throwing, anticipated up to 5 months before the sowing also it does not influence statistically the soy grain production, the accumulation of $\mathrm{P}$ and $\mathrm{K}$ in the leaves, the weight of 100 seeds and the first pod height related to the soil. It was observed a significant increase for all the evaluated characteristics indicating $\mathrm{P}$ and $\mathrm{K}$ accumulation in the soil with the successive croppings.
\end{abstract}

Key-words: Glycine max, multiphosphat magnesian, residual effect, fertilizers.

${ }^{1}$ Engenheira Agrônoma, Doutora, Professora Titular do Instituto de Ciências Agrárias, Universidade Federal de Uberlândia. Av. Amazonas s/n, BI. 4C, SI. 09. Campus Umuarama, CEP 38400-902, C.P. 593, Uberlândia-MG. E-mail: rmqlana@iciag.ufu.br

${ }^{2}$ Aluno de graduação do curso de Agronomia da Universidade Federal de Uberlândia:

${ }^{3}$ Aluno de graduação do curso de Agronomia da Universidade Federal de Uberlândia, Bolsista Fapemig;

${ }^{4}$ Engenheiro Agrônomo, Doutor, Pesquisador do Instituto de Ciências Agrárias da Universidade Federal de Uberlândia, Bolsista do CNPq;

${ }^{5}$ Engenheira Agrônoma, Doutora em Genética , Professora Adjunto da Universidade Federal de Minas Gerais. 


\section{INTRODUÇÃO}

A recomendação de adubação para o sistema de plantio direto se baseia em critérios adotados ao preparo convencional e nos leva a buscar técnicas específicas de manejo da adubação como a produção de matéria seca para cobertura do solo, melhorando a eficiência dos fertilizantes e reduzindo os custos de produção.

Os solos de cerrado apresentam elevada taxa de fixação de fósforo e lixiviação do potássio, o que reduz a produtividade da soja nestes solos.

O aproveitamento dos nutrientes pela cultura nem sempre ocorre de maneira eficiente. Em boas condições, a recuperação do fósforo e potássio adicionados varia 5 a $20 \%$ e de 30 a $60 \%$, respectivamente, do total aplicado no primeiro ano. Os cultivos seguintes continuam aproveitando o fósforo residual, sendo que até $70 \%$ do fósforo total aplicado poderá ser aproveitado com os cultivos sucessivos (11).

O manejo adequado do fertilizante fosfatado varia com características específicas do solo, da cultura entre outros, não podendo adotar práticas de manejo generalizadas e ignorando as particularidades do solo de diferentes locais. É preciso identificar as características químicas, físicas e biológicas de cada solo e incorporar novas técnicas como a adoção do sistema de plantio direto e novas técnicas de fertilização, visando à minimização de alguns problemas enfrentados pelo produtor durante a semeadura.

O manejo de adubação em sistema de plantio direto, em solos corrigidos, é feito distribuindo superficialmente o fertilizante em doses proporcionais à exportação das culturas. Isso diminui a necessidade de incorporação dos nutrientes, viabilizando a prática de adubação de pré-semeadura. Geralmente, tal prática tem sido feita a lanço, com esparramadeira de calcário ou distribuidor tipo cocho, previamente ao estabelecimento de culturas de espaçamento estreito, como soja e arroz. Nessa época são aplicados todo o fósforo e parte do potássio, além do enxofre, magnésio e micronutrientes, todos sobre a palhada dessecada. O restante do nitrogênio e/ou potássio é aplicado em cobertura.

A necessidade de fósforo pode ser menor no sistema de plantio direto, em virtude da não incorporação do adubo, reduzindo as perdas pela fixação. A aplicação a lanço sobre a superfície, sem incorporação, acarreta menor fixação de fósforo, aumentando conseqüentemente a disponibilidade na camada mais superficial (17).

A maior disponibilidade e o melhor aproveitamento do fósforo em sistema de plantio direto têm evidenciado a possibilidade através do tempo, de se reduzir a quantidade de adubo fosfatado a ser aplicado, uma vez superado os intervalos críticos de nutrientes no solo (10). Assim, no sistema de plantio direto, a adubação fosfatada e potássica, a lanço, superficial, antecipando a semeadura, poderá contribuir para o avanço no sistema de produção de soja.

Para difusão dessa tecnologia, há necessidade de adequar fontes de fósforo e potássio de liberação gradual visando reduzir a fixação de $\mathrm{P}$ e diminuir a lixiviação do $\mathrm{K}$ no solo. Assim, o objetivo desse trabalho foi avaliar a eficiência da aplicação superficial antecipada do fertilizante fosfatado e potássico, em pré-semeadura, sob sistema de plantio direto, na cultura da soja durante três anos agrícolas.

\section{MATERIAL E MÉTODOS}

O experimento foi conduzido nas safras 1999/ 2000, 2000/2001 e 2001/2002 em um Latossolo Vermelho Eutrófico, textura argilosa (530 g kg-1 de argila), relevo suave, anteriormente cultivado com pastagens, localizado na fazenda experimental Capim Branco da Universidade Federal de Uberlândia, em UberlândiaMG; latitude $18^{\circ} 55^{\prime}$ 'S; longitude $48^{\circ} 17^{\prime} \mathrm{W}$ e altitude $872 \mathrm{~m}$. Os dados médios de precipitação pluvial e temperatura se encontram nas Figuras 1 e 2.

A análise do solo, dos primeiros $20 \mathrm{~cm}$, revelou as seguintes características químicas: $\mathrm{pH}\left(\mathrm{H}_{2} \mathrm{O}\right.$ $1: 2,5)=6,0 ; \mathrm{M} . \mathrm{O}$. (Walkley Black) $=28 \mathrm{~g} \cdot \mathrm{kg}^{-1} ; \mathrm{P}$ $($ Mehlich1 $)=1,0 \mathrm{mg} \cdot \mathrm{dm}^{-3} ; \mathrm{K}($ Mehlich1 $)=65,1 \mathrm{mg} \cdot \mathrm{dm}^{-3}$; $\mathrm{Ca}=30 \mathrm{mmol}_{\mathrm{c}} \mathrm{dm}^{-3} ; \mathrm{Mg}=24 \mathrm{mmol}_{\mathrm{c}} \mathrm{dm}^{-3}$ e $\mathrm{Al}=0,0$ $\mathrm{mmol}_{\mathrm{c}} \mathrm{dm}^{-3}$.

O experimento foi instalado em área antes cultivada com pastagem de Brachiaria decumbens. O preparo do solo constituiu de uma aração a $20 \mathrm{~cm}$ de profundidade para semeadura do milheto como cultura de inverno para a formação de palhada, iniciando o sistema de plantio direto. Logo após foram demarcadas as parcelas, constituídas de seis linhas com 5,0 m de comprimento, com espaçamento entre linhas de 0,45 m, correspondendo a uma área total por parcela de $13,5 \mathrm{~m}^{2}$. Considerou-se como área útil as duas linhas centrais, eliminando-se $0,5 \mathrm{~m}$ em cada extremidade (área útil de $3,6 \mathrm{~m}^{2}$ por parcela). De acordo com a análise do solo, não houve necessidade de aplicação de calcário para a correção da acidez do solo.

O delineamento experimental usado foi o de blocos ao acaso com cinco tratamentos e cinco repetições. As adubações foram realizadas a lanço, superficial, antecipada, nos meses de julho, agosto, setembro, outubro e novembro (juntamente com a semeadura) a cada ano de condução do experimento. Utilizou-se como fertilizante o multifosfato magnesiano, formulação 00-16-16 (fósforo com 16\% sol. CNA e $8 \%$ sol. $\mathrm{H}_{2} \mathrm{O}$ ) na dose de $625 \mathrm{~kg} \mathrm{ha}^{-1}$, fornecendo $100 \mathrm{~kg} \cdot \mathrm{ha}^{-1}$ de $\mathrm{K}_{2} \mathrm{O}$ e $100 \mathrm{~kg} \cdot \mathrm{ha}^{-1}$ de $\mathrm{P}_{2} \mathrm{O}_{5}$, segundo recomendação de Ribeiro et al. (14).

As adubações de pré-semeadura foram realizadas entre os dias 10 e 20 de cada mês em todos os anos agrícolas. A aplicação do multifosfato

\footnotetext{
${ }^{1 *}$ Constituição do produto segundo o fabricante que utiliza o nome comercial Bunge Fertilizantes, São Paulo-SP.
} 
magnesiano nas parcelas foi realizada manualmente, a lanço sem incorporação.

O multifosfato magnesiano é constituído em: 160 g. $\mathrm{Kg}^{-1}$ de $\mathrm{P}_{2} \mathrm{O}_{5} ; 60 \mathrm{~g} . \mathrm{Kg}^{-1}$ de $\mathrm{K}_{2} \mathrm{O} ; 100 \mathrm{~g} \cdot \mathrm{kg}^{-1} \mathrm{de}$ Ca; 22 g. Kg ${ }^{-1}$ de $\mathrm{Mg} ; 4$ g. $\mathrm{Kg}^{-1}$ de $\mathrm{Zn} ; 2 \mathrm{~g} \cdot \mathrm{Kg}^{-1}$ de B; 3 g. $\mathrm{Kg}^{-1}$ da $\mathrm{Mn} ; 0,1 \mathrm{~g} \cdot \mathrm{Kg}^{-1}$ de Mo; e $0,025 \mathrm{~g} \cdot \mathrm{Kg}^{-1}$ de Co.

A cultivar de soja usada foi a MG/BR-46 Conquista, cujas sementes foram tratadas com Carboxim + Thiram na dose de $250 \mathrm{~mL} 100 \mathrm{~kg}^{-1}$ de sementes e inoculadas com Bradyrhizobium japonicum na dose

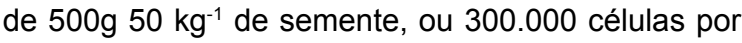
semente, segundo EMBRAPA (2).

A semeadura foi efetuada em novembro, em sistema de plantio direto com a dessecação do milheto, utilizando Glifosato na dosagem de 2,0 L.ha $^{-1}$ antes da semeadura. Ao atingir o terceiro trifólio definitivo, estádio V3 de acordo com Fehr et al. (6), foram realizadas aplicações de herbicidas: graminicida (Fluazifop-p-butyl 1,5 L.ha-1) e latifolicida (Chlorimuron-etil $60 \mathrm{~g} \mathrm{ha}^{-1}$ ) ambos seletivos para a cultura da soja. Para o controle de pragas, utilizou-se o inseticida Deltametrin na dosagem de 0,3 L.ha- ${ }^{-1}$.

Para avaliar os teores de Fósforo e Potássio nas folhas, foram coletadas amostras no florescimento pleno da soja, estádio R2 (6) retirando-se a terceira folha completamente desenvolvida, a partir do ápice das plantas conforme Bataglia et al. (1). Estas folhas foram secas em estufa de ventilação forçada a $65^{\circ} \mathrm{C}$, até peso constante. Em seguida, elas foram moídas para análise química de $\mathrm{P}$ e $\mathrm{K}$ de acordo com a metodologia descrita por Bataglia et al (1).

Antes da colheita, com a soja completamente seca, estádio R8 (6), mediu-se a altura da primeira vagem em relação ao solo, fazendo a média de cinco plantas por parcela útil entre os diferentes tratamentos.

A avaliação de produtividade foi realizada pela retirada das plantas da área útil da parcela, e estimando-se a produtividade por hectare. Após a colheita, avaliou-se o peso de cem sementes. Para avaliação dos teores de P e do K (Mehlich1) foram coletadas sub-amostras de solo nas linhas e nas entrelinhas, na profundidade de $0-20 \mathrm{~cm}$, após os cultivos.

Efetuou-se a análise de variância para os parâmetros estudados, bem como a comparação entre os diferentes anos agrícolas, sendo as médias comparadas pelo teste de Tukey, de $5 \%$ de probabilidade.

\section{RESULTADOS}

\section{Produtividade}

Não houve diferença significativa sobre a produtividade da soja, entre as diferentes épocas de aplicação do fertilizante, aplicado a lanço, antecipada até cinco meses antes da semeadura, dentro do mesmo ano agrícola (Tabela 1).

Comparando-se o primeiro com o terceiro ano de cultivo, verifica-se que a produtividade variou em média, de $2.483 \mathrm{~kg} \mathrm{ha}^{-1}$, no primeiro ano, para 2.928 $\mathrm{kg} \mathrm{ha}^{-1}$ no terceiro, representando um aumento significativo de $18 \%$ (Tabela 1 ).

TABELA 1 - Médias de produtividade $\left(\mathrm{kg} \mathrm{ha}^{-1}\right)$, em diferentes épocas de adubação na soja, cultivar MG/BR-46 Conquista. UFU Uberlândia-MG 1999/2000 - 2000/2001 - 2001/2002.

\begin{tabular}{lccc}
\hline & \multicolumn{3}{c}{ Produtividade média $\left(\mathrm{kg} \mathrm{ha}^{-1}\right)$} \\
\hline \multicolumn{1}{c}{ Épocas de Aplicação } & Safra 99/00 & Safra 00/01 & Safra 01/02 \\
\hline Julho & $2.455 \mathrm{~b}$ & $2.598 \mathrm{~b}$ & $2.999 \mathrm{a}$ \\
Agosto & $2.417 \mathrm{~b}$ & $2.519 \mathrm{~b}$ & $2.897 \mathrm{a}$ \\
Setembro & $2.694 \mathrm{~b}$ & $2.714 \mathrm{~b}$ & $2.916 \mathrm{a}$ \\
Outubro & $2.344 \mathrm{~b}$ & $2.833 \mathrm{~b}$ & $2.869 \mathrm{a}$ \\
Novembro & $2.505 \mathrm{~b}$ & $2.623 \mathrm{~b}$ & $2.963 \mathrm{a}$ \\
Média geral & 2.483 & 2.657 & 2.928 \\
Teste de F & $0,51 \mathrm{NS}$ & $0,95 \mathrm{NS}$ & $0,13 \mathrm{NS}$ \\
DMS & 795,552 & 535,765 & 620,353 \\
C.V. (\%) & 16,54 & 10,40 & 10,93 \\
\hline
\end{tabular}

Médias seguidas pela mesma letra, minúscula na linha, não diferem entre si, pelo teste de Tukey a 5\%.

\section{Teores de fósforo e potássio foliar}

Com relação aos teores de $\mathrm{P}$ e $\mathrm{K}$ foliar, não se observou diferença significativa entre os tratamentos no mesmo ano de cultivo (Tabela 2). O teor foliar de P diminuiu na safra de 2000/2001, devido ao período de estiagem, durante o ciclo da cultura. No entanto, os teores médios de K aumentaram com os cultivos sucessivos, indicando que em SPD, solo argiloso, deve-se considerar o efeito residual do fertilizante potássico na recomendação de adubação. 
LANA, F.R.M.Q. et al. Adubação superficial com fósforo...

TABELA2 - Médias de fósforo foliar $\left(\mathrm{g} \mathrm{kg}^{-1}\right)$, em diferentes épocas de adubação na soja,cultivar MG/BR-46 Conquista. UFU UberlândiaMG 1999/2000 - 2000/2001-2001/2002.

\begin{tabular}{lcccccc}
\hline & \multicolumn{3}{c}{ Fósforo foliar $\left(\mathrm{g}^{\prime} \mathrm{kg}^{-1}\right)$} & \multicolumn{3}{c}{ Potássio foliar $\left(\mathrm{g} \cdot \mathrm{kg}^{-1}\right)$} \\
\multicolumn{1}{c}{ Épocas de } & Safra 99/00 & Safra 00/01 & Safra 01/02 & Safra 99/00 & Safra 00/01 & Safra 01/02 \\
\hline Julho & $2,72 \mathrm{a}$ & $1,34 \mathrm{~b}$ & $2,60 \mathrm{a}$ & $15,2 \mathrm{c}$ & $20,1 \mathrm{~b}$ & $23,5 \mathrm{a}$ \\
Agosto & $2,54 \mathrm{a}$ & $1,34 \mathrm{~b}$ & $2,52 \mathrm{a}$ & $14,7 \mathrm{c}$ & $19,7 \mathrm{~b}$ & $23,0 \mathrm{a}$ \\
Setembro & $2,66 \mathrm{a}$ & $1,26 \mathrm{~b}$ & $2,72 \mathrm{a}$ & $15,6 \mathrm{c}$ & $19,9 \mathrm{~b}$ & $21,9 \mathrm{a}$ \\
Outubro & $2,88 \mathrm{a}$ & $1,40 \mathrm{~b}$ & $2,68 \mathrm{a}$ & $15,5 \mathrm{c}$ & $20,9 \mathrm{~b}$ & $22,5 \mathrm{a}$ \\
Novembro & $2,72 \mathrm{a}$ & $1,38 \mathrm{~b}$ & $2,66 \mathrm{a}$ & $15,3 \mathrm{c}$ & $20,3 \mathrm{~b}$ & $22,4 \mathrm{a}$ \\
Média geral & 2,70 & 1,34 & 2,63 & 15,26 & 20,18 & 22,66 \\
Teste de F & $1,33 \mathrm{NS}$ & $0,97 \mathrm{NS}$ & $0,64 \mathrm{NS}$ & $0,67 \mathrm{NS}$ & $0,93 \mathrm{NS}$ & $0,59 \mathrm{NS}$ \\
DMS & 0,460 & 0,236 & 0,419 & 2,214 & 2,063 & 3,417 \\
C.V. (\%) & 8,80 & 9,08 & 8,21 & 4,90 & 5,27 & 7,78 \\
\hline
\end{tabular}

Médias seguidas pela mesma letra, minúscula na linha, não diferem entre si, pelo teste de Tukey a $5 \%$.

\section{Altura da $1^{\text {a }}$ vagem em relação ao solo e peso de cem sementes}

A altura da $1^{\text {a }}$ vagem em relação ao solo e o peso de cem sementes não diferiram com relação às diferentes épocas de adubação (Tabela 3), indicando que a época de aplicação do adubo fosfatado e potássico a lanço, em pré-semeadura, não alterou essas características dentro de um mesmo ano de cultivo. No entanto, quando se comparam os três anos agrícolas, nota-se que houve um acréscimo no peso de cem sementes no último ano. Para a altura da inserção da primeira vagem, comparando-se o primeiro com o terceiro ano de cultivo, verifica-se que a altura média variou de $14,72 \mathrm{~cm}$ a $19,15 \mathrm{~cm}$, o que significa um acréscimo significativo de $30 \%$.

$\mathrm{Na}$ cultura da soja, o peso das sementes e a altura da $1^{\text {a }}$ vagem em relação ao solo, estão estreitamente ligados ao nível de adubação fosfatada. Essas características são de grande importância, principalmente quando a colheita é mecanizada, pois pode reduzir diversas perdas no processo de colheita.

TABELA3 - Médias de altura da $1^{\text {a }}$ vagem em relação ao solo $(\mathrm{cm})$ e peso de cem sementes $(\mathrm{g})$, em diferentes épocas de adubação na soja, cultivar MG/BR-46 Conquista. UFU Uberlândia-MG 1999/2000-2000/2001-2001/2002.

\begin{tabular}{lcccccc}
\hline & \multicolumn{3}{c}{ Altura da 1 ${ }^{\mathrm{a}}$ vagem $(\mathrm{cm})$} & \multicolumn{2}{c}{ Peso de cem sementes $(\mathrm{g})$} \\
\hline \multicolumn{1}{c}{ Épocas de } & Safra 99/00 & Safra 00/01 & Safra 01/02 & Safra 99/00 & Safra 00/01 & Safra 01/02 \\
\multicolumn{1}{c}{ aplicaço } & $14,30 \mathrm{c}$ & $16,24 \mathrm{~b}$ & $19,32 \mathrm{a}$ & $14,55 \mathrm{~b}$ & $15,29 \mathrm{~b}$ & $17,44 \mathrm{a}$ \\
Julho & $14,82 \mathrm{C}$ & $16,61 \mathrm{~b}$ & $19,26 \mathrm{a}$ & $14,42 \mathrm{~b}$ & $15,35 \mathrm{~b}$ & $16,56 \mathrm{a}$ \\
Agosto & $15,00 \mathrm{c}$ & $17,57 \mathrm{~b}$ & $18,93 \mathrm{a}$ & $14,88 \mathrm{~b}$ & $15,14 \mathrm{~b}$ & $17,15 \mathrm{a}$ \\
Setembro & $14,90 \mathrm{c}$ & $17,24 \mathrm{~b}$ & $18,93 \mathrm{a}$ & $14,63 \mathrm{~b}$ & $15,44 \mathrm{~b}$ & $17,39 \mathrm{a}$ \\
Outubro & $14,60 \mathrm{C}$ & $16,17 \mathrm{~b}$ & $19,29 \mathrm{a}$ & $14,85 \mathrm{~b}$ & $15,26 \mathrm{~b}$ & $17,25 \mathrm{a}$ \\
Novembro & 14,72 & 16,77 & 19,15 & 14,67 & 15,30 & 17,16 \\
Média geral & $0,24 \mathrm{NS}$ & $0,61 \mathrm{NS}$ & $0,05 \mathrm{NS}$ & $1,46 \mathrm{NS}$ & $0,08 \mathrm{NS}$ & $0,56 \mathrm{NS}$ \\
Teste de F & 2,482 & 3,396 & 3,871 & 1,875 & 1,667 & 2,066 \\
DMS & 8,70 & 10,45 & 10,43 & 6,60 & 5,62 & 6,21 \\
C.V. (\%) & & & & & &
\end{tabular}

Médias seguidas pela mesma letra, minúscula na linha, não diferem entre si, pelo teste de Tukey a 5\%.

\section{Fósforo e potássio residual}

Com os cultivos sucessivos, observou-se que a cultura da soja respondeu a uma melhoria das características químicas do solo, havendo uma elevação gradativa dos teores de fósforo e potássio residuais com os cultivos sucessivos, quando aplicado a lanço em sistema de plantio direto, o que deve ter refletido na produtividade (Tabela 4 ).

Comparando-se o primeiro com o terceiro ano de cultivo, verifica-se que o teor médio de $\mathrm{P}$ no solo foi elevado de $1,2 \mathrm{mg}_{\mathrm{dm}} \mathrm{d}^{-3}$ para $6,0 \mathrm{mg} \cdot \mathrm{dm}^{-3} \mathrm{e}$ o teor médio de $\mathrm{K}$ no solo de $67,4 \mathrm{mg} \cdot \mathrm{dm}^{-3}$ para $83,3 \mathrm{mg} \cdot \mathrm{dm}^{-3}$, o que significa um acréscimo de $400 \%$ para o P e $42 \%$ para o K. Sendo o solo argiloso e cultivado em sistema plantio direto verifica-se acúmulo de $\mathrm{K}$ no solo 
com os cultivos sucessivos. Geralmente, em solo cultivado em sistema de plantio convencional (aração e gradagem), solo arenoso, com baixo teor de matéria orgânica e baixa capacidade de troca catiônica, o K é facilmente lixiviado, dado o baixo poder de retenção nas cargas negativas do solo. No entanto, observouse que em condições de sistema plantio direto, solo argiloso e baixa precipitação pluvial, a lixiviação do K é reduzida, viabilizando a prática de adubação potássica antecipada.

TABELA 4 - Médias de fósforo e potássio residual no solo $\left(\mathrm{mg}^{\left.-\mathrm{dm}^{-3}\right)}\right.$, em diferentes épocas de adubação na soja, cultivar MG/BR-46 Conquista. UFU Uberlândia-MG, 2002.

\begin{tabular}{lcccccc}
\hline & \multicolumn{3}{c}{ Fósforo residual $\left(\mathrm{mg}^{\left.-1 \mathrm{dm}^{-3}\right)}\right.$} & \multicolumn{3}{c}{ Potássio residual $\left(\mathrm{mg}^{-3} \mathrm{dm}^{-3}\right)$} \\
\hline \multicolumn{1}{c}{ Épocas de aplicação } & Safra 99/00 & Safra 00/01 & Safra 01/02 & Safra 99/00 & Safra 00/01 & Safra 01/02 \\
\hline Julho & $1,10 \mathrm{c}$ & $4,62 \mathrm{~b}$ & $5,90 \mathrm{a}$ & $66,0 \mathrm{c}$ & $75,0 \mathrm{~b}$ & $81,2 \mathrm{a}$ \\
Agosto & $1,20 \mathrm{C}$ & $4,60 \mathrm{~b}$ & $5,96 \mathrm{a}$ & $67,0 \mathrm{c}$ & $80,1 \mathrm{~b}$ & $85,4 \mathrm{a}$ \\
Setembro & $1,20 \mathrm{c}$ & $4,72 \mathrm{~b}$ & $6,06 \mathrm{a}$ & $67,0 \mathrm{c}$ & $80,0 \mathrm{~b}$ & $81,4 \mathrm{a}$ \\
Outubro & $1,30 \mathrm{c}$ & $4,36 \mathrm{~b}$ & $5,98 \mathrm{a}$ & $69,0 \mathrm{c}$ & $76,2 \mathrm{~b}$ & $86,6 \mathrm{a}$ \\
Novembro & $1,20 \mathrm{c}$ & $3,68 \mathrm{~b}$ & $6,14 \mathrm{a}$ & $68,0 \mathrm{c}$ & $74,2 \mathrm{~b}$ & $81,7 \mathrm{a}$ \\
Média geral & 1,20 & 4,39 & 6,00 & 67,4 & 77,1 & 83,3 \\
Teste de F & $0,38 \mathrm{NS}$ & $0,44 \mathrm{NS}$ & $0,13 \mathrm{NS}$ & $0,62 \mathrm{NS}$ & $0,10 \mathrm{NS}$ & $0,84 \mathrm{NS}$ \\
DMS & 0,16 & 2,74 & 1,10 & 4,63 & 30.26 & 43,60 \\
CV\% & 8,7 & 32,20 & 9,45 & 10,21 & 21,4 & 27,1 \\
\hline
\end{tabular}

Médias seguidas pela mesma letra, minúscula na linha, não diferem entre si, pelo teste de Tukey a $5 \%$.

\section{DISCUSSÂO}

\section{Produtividade}

A adubação utilizada no experimento acarretou aumento na produtividade, comparando-se o primeiro com o terceiro ano sucessivo de cultivo, demonstrando resposta da soja à aplicação em $\mathrm{P}$ e $\mathrm{K}$, bem como a eficiência do fertilizante aplicado a lanço em pré-semeadura.

Considerando as condições climáticas da região do Triângulo Mineiro, que é de temperatura e luminosidade alta e precipitação pluvial baixa nos meses de julho a outubro, concentrando as chuvas no período de novembro a março (Figuras 1 e 2), a aplicação antecipada, até cinco meses antes da semeadura, do fertilizante multifosfato magnesiano, não comprometeu a produtividade da soja, bem como, os parâmetros que influenciam a produtividade.

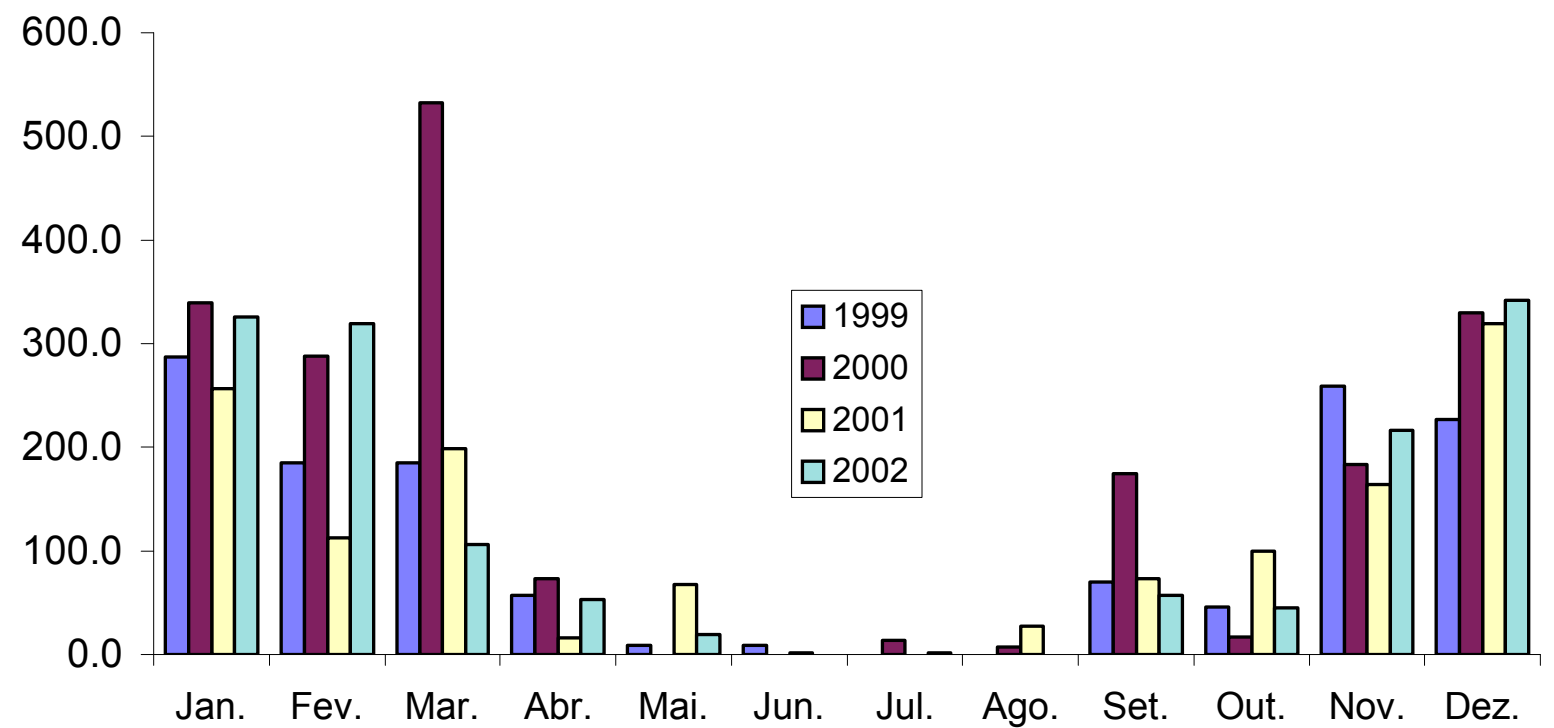

FIGURA 1 - Precipitação pluvial no município de Uberlândia entre os anos de 1999 e 2002. Fonte: Instituto Nacional de Metereologia

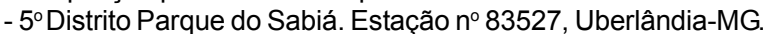


Os dados de precipitação pluvial e temperaturas médias dos anos de 1990 a 2002, na cidade de Uberlândia, comprovam que basicamente não há perdas do $\mathrm{K}$ por lixiviação, visto que as chuvas se concentram a partir de novembro (Figuras 1 e 2 ).

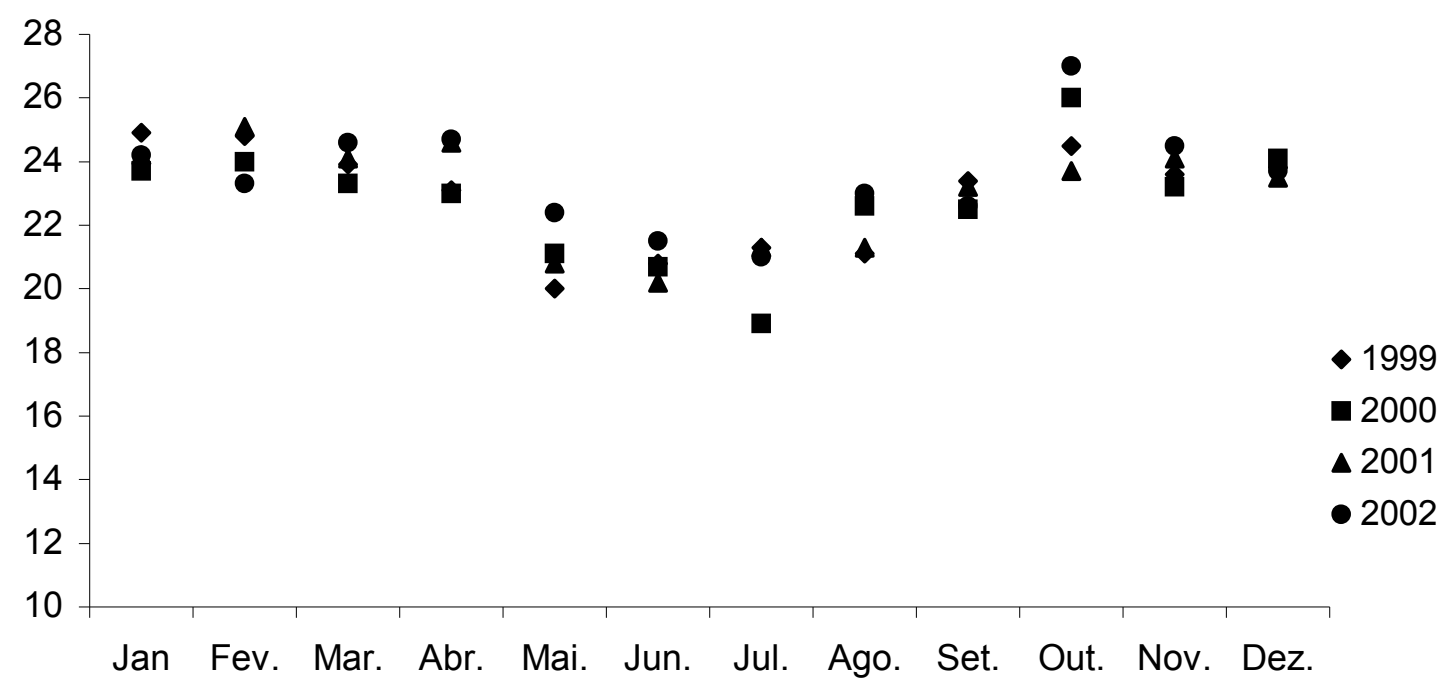

FIGURA 2 - Temperaturas no município de Uberlândia entre os anos de 2000 e 2001. Fonte: Instituto Nacional de Metereologia - $5^{\circ}$ Distrito Parque do Sabiá. Estação n 83527, Uberlândia-MG.

Há uma relação direta entre fertilidade do solo e produtividade da planta, sendo mantidos os demais fatores de produção em níveis não limitantes. A planta tem seu crescimento diretamente dependente da concentração de $\mathrm{P}$ e K na solução do solo, ou do fator intensidade (I), e, indiretamente, do fator quantidade (Q) e do fator capacidade de $\mathrm{P}$ e $\mathrm{K}$ do solo $(\mathrm{Q} / \mathrm{I})$, que governam o valor de I. Os modelos de $P$ no solo, dada a imobilidade desse elemento no solo, são altamente dependentes da difusão, decorrente do suprimento desse elemento, da disponibilidade de água, compactação do solo, adição de $\mathrm{P}$ e outros (11).

É importante ressaltar que a aplicação antecipada do fertilizante fosfatado e potássico apresentaram produtividades estatisticamente equivalentes á aplicação na época da semeadura, considerando o período de veranico que ocorre de agosto a outubro nesta região, viabilizando a aplicação antecipada do fertilizante. A aplicação a lanço e antecipada do fertilizante não acarretou diminuição nos teores de $\mathrm{P}$ pela fixação. Esta prática foi viável em condições de solo com a acidez corrigidos ( $\mathrm{pH}=6,0)$ e ausência de $\mathrm{Al}$ trocável, onde a fixação do $\mathrm{P}$ é bastante reduzida.

Com cultivos subseqüentes, esse efeito desaparece, pois os fertilizantes aplicados de forma localizada passam a ser misturados com o resto da camada superficial do solo. Na prática, entretanto, os agricultores tendem a aplicar o fertilizante no sulco de semeadura, ou seja, de forma localizada (7).

Segundo Lopes et al. (9), apesar da aplicação superficial de fósforo ser geralmente o modo menos eficiente para adubar as culturas plantadas em linha, o sistema plantio direto é uma exceção na maioria das situações. Quando uma cultura como o milho é plantada em soqueira morta ou com resíduos de culturas sem aração prévia, o fósforo aplicado superficialmente proporciona tão bom efeito quanto a aplicação localizada, desde que os teores de fósforo no solo sejam médios a altos, o que explica a resposta melhor no terceiro ano, onde os níveis de $\mathrm{P}$ no solo passaram de baixo no primeiro ano, para médio no segundo ano. Segundo estes autores, com resíduos na superfície, os níveis de umidade encorajam o enraizamento pouco profundo. Isso faz com que as raízes utilizem o fósforo da superfície ou próximo a ela.

Muitos experimentos têm sido desenvolvidos na região de cerrado cultivado em sistema plantio direto para estudar métodos de aplicação de fertilizantes fosfatados. Considerando-se resultados em longo prazo, a produção acumulada tem sido função mais especificamente do acúmulo de $\mathrm{P}$ com os cultivos sucessivos do que do método de aplicação do fertilizante fosfatado.

Usualmente, aplicações de doses mais elevadas a lanço têm proporcionado maiores rendimentos que aquelas localizadas, nos primeiros cultivos, tendo em vista o maior desenvolvimento radicular proporcionado pela aplicação a lanço (5, 4 e 12).

Vale ressaltar que, por ocasião da abertura de 
novas áreas para a produção de grãos, a combinação de aplicações de adubação fosfatada a lanço e posteriores adubações de manutenção no sulco de plantio são recomendadas (8).

Segundo Sá (15), o comportamento do fósforo no sistema de plantio direto difere do preparo convencional em três pontos básicos: a) o não revolvimento do solo reduz o contato entre os colóides e o íon fosfato, amenizando as reações de adsorção; b) a manutenção dos resíduos culturais sem a sua incorporação ao solo resulta na formação de linha com maior concentração de fósforo devido à adubação das culturas; c) a mineralização lenta e gradual dos resíduos proporciona a liberação e redistribuição de formas orgânicas de $P$ mais estáveis e menos susceptíveis às reações de adsorção.

A integração desses três pontos básicos mobilizaria uma série de transformações nas frações orgânicas e inorgânicas, de ordem biológica e química, podendo reduzir, sensivelmente, o caminho em direção à adsorção e fixação de P. Neste caso, o teor de fósforo disponível para a planta seria mais elevado, possibilitando maior coeficiente de aproveitamento pelas culturas. Essa é a possível explicação por que áreas com mais de 10 anos sob plantio direto em sistema de rotação no Estado do Paraná têm apresentado, em média, respostas a doses de $\mathrm{P}_{2} \mathrm{O}_{5}$ variando de 30 a $60 \mathrm{~kg} \cdot \mathrm{ha}^{-1}$, para tetos de produtividade de milho maiores que $9000,00 \mathrm{~kg} \cdot \mathrm{ha}^{-1}$ (16).

Com os cultivos subseqüentes, em sistema de plantio direto, observa-se um acúmulo de fósforo e potássio no solo, acarretando o aumento de $\mathrm{P}$ e $\mathrm{K}$, enquadrando-os ao nível classificado como "bom", segundo Ribeiro et al (14). Á partir deste nível se faz a adubação com base na exportação destes nutrientes pela cultura.

\section{Teores de $\mathrm{P}$ e $\mathrm{K}$ foliares e $\mathrm{P}$ e $\mathrm{K}$ residuais do solo}

Na safra 2000/2001 verificou-se uma redução nos teores $\mathrm{P}$ e $\mathrm{K}$ residuais do solo em relação aos outros anos, motivado pela semeadura tardia do experimento, levando a cultura a atravessar períodos com menor precipitação pluvial em relação ao demais anos (Figura 1), o que interferiu no mecanismo de difusão, que é controlado pela água, com redução da absorção de fósforo pela planta.

Segundo Raij (13), os teores de fósforo e potássio nas folhas, considerados ideais, estão entre 2,6-5,0 $\mathrm{g} \mathrm{kg}^{-1}$ para $\mathrm{P}$ e 17,1-25,0 $\mathrm{g} \mathrm{kg}^{-1}$ para $\mathrm{K}$, valores estes próximos dos teores médios encontrados no experimento. Pelos dados apresentados anteriormente, ficou evidente que o fósforo e potássio têm reflexos positivos na produção das culturas subseqüentes, por isso é importante saber quantificar esse efeito residual. Sua quantificação não é simples, resultado da interação de fatores como o tipo de solo, fonte, dose, método de aplicação e preparo do solo.

Para uma produção de $1000 \mathrm{~kg} \mathrm{ha}^{-1}$, a quantidade total de $\mathrm{P}_{2} \mathrm{O}_{5}$ e $\mathrm{K}_{2} \mathrm{O}$ acumulado em sua biomassa - grãos e restos culturais - fica em torno de 15,4 kg.ha-1 e $38 \mathrm{~kg} \cdot \mathrm{ha}^{-1}$, respectivamente (3). Essa quantidade de $\mathrm{P}$ e $\mathrm{K}$ deverá ser suprida pelo solo, com ou sem a ajuda de fertilizantes; no caso de solos pobres, com a ajuda de fertilizantes, para que mais $\mathrm{K}$ e $\mathrm{P}$-disponíveis entrem em contato com a planta por fluxo difusivo (11).

Pelos resultados obtidos verifica-se que a aplicação antecipada de fertilizantes não alterou os teores de $\mathrm{P}$ e $\mathrm{K}$ foliares e $\mathrm{P}$ e $\mathrm{K}$ residuais do solo, gerando algumas vantagens aos produtores, como: redução do custo total de produção, pois a compra e aplicação antecipada do fertilizante diminuem em até $10 \%$ os custos variáveis da lavoura; maior rendimento operacional na semeadura, pois diminui os reabastecimentos e elimina o problema de semeaduras tardias com diminuição de produtividade; uniformidade de semeadura, não havendo variação na profundidade de semeadura; otimiza o uso do maquinário e mãode-obra ociosa nos meses de entressafra; diminui o problema de estoques de adubo na empresa distribuidora e permite que as empresas comercializem o adubo já aplicado.

\section{CONCLUSÃO}

A adubação com fósforo e potássio na instalação do sistema de plantio direto, a lanço, antecipada até cinco meses antes da semeadura, não afetou as variáveis: produtividade, teores de P e K foliar, altura da primeira vagem em relação ao solo e peso de cem sementes, na cultura da soja, para o mesmo ano agrícola. Houve aumento significativo da produtividade de soja com os cultivos sucessivos, independentemente das épocas de aplicação dos fertilizantes. Verificou-se efeito residual para $\mathrm{P}$ e $\mathrm{K}$, em sistema de plantio direto, com os cultivos sucessivos. 
LANA, F.R.M.Q. et al. Adubação superficial com fósforo...

\section{REFERÊNCIAS BIBLIOGRAFICAS}

1. BATAGLIA, O.C.; FURLANI, A.M.C.; TEIXEIRA, J.P.F.; FURLANI, P.R.; GALLO, J.R. Métodos de análise química de plantas. Campinas: Instituto Agronômico, 1985. 48p. (Boletim Técnico, 78).

2. EMPRESA BRASILEIRA DE PESQUISA AGROPECUÁRIA. Centro Nacional de Pesquisa de Soja-CNPSo, Londrina. Recomendações técnicas para a cultura da soja na região central do Brasil-2001/2002. Londrina, 2001. 267 p. (Documentos, 167).

3. EMPRESA BRASILEIRADE PESQUISAAGROPECUÁRIA. Tecnologia de produção de soja - região central do Brasil 2004. Londrina: Embrapa Soja: Embrapa Agropecuária Oeste: Embrapa Cerrado: EPAMIG: Fundação Triangulo, 2003. 237p.

4. ERNANI, P.R., STECKLING, C., BAYER, C.. Características químicas de solo e rendimento de massa seca de milho em função do método de aplicação de fosfato, em dois níveis de acidez. Revista Brasileira de Ciência do Solo, Viçosa, v.25, n.4, p. 939-946, 2001.

5. FAGERIA, N.K.; STONE, L.S.; SANTOS, A.B. Maximização da eficiência de produção das culturas. Brasília: Embrapa Comunicação para Transfência de Tecnologia; Santo Antônio de Goiás : Embrapa Arroz e Feijão, 1999. 294p.

6. FEHR, W. R.; CAVINESS, C. E.; BURMOOD, D. T.; PENNINGTON, J. S. Stage of development descriptions for soybeans, Glycine max (L) Merrill. Crop Science, Madison, v.11, n.6, p.929-931, 1977.

7. GOEDERT, W.J. Management of acid tropical soils in the savannas of South America. In: IBSRAM (International Board for Soil Research and Management). Management of acid tropical soils for sustainable agriculture: proceeding of an IBSRAM inaugural workshop. Bangkok, Thailand, p. 109-127, 1987

8. LOPES, A. S. Solos sob "cerrado": características, propriedades e manejo. Piracicaba, POTAFÓS, 1983. 162p.

9. LOPES, A. S., GUILHERME, L. R. G.; MARQUES, R. Métodos de aplicação de fertilizantes fosfatados. In: Guia de Fertilidade do Solo. Lavras. 1999. CD ROM.

10. MUZILLI, O. O plantio direto no Brasil. In: FANCELLI, A.L.; TORRADO, P.V. (Coord.). Atualização em plantio direto. Campinas: Fundação Cargill, 1985. Cap.1, p.3-16.

11. NOVAIS, R.F.; SMYTH, T.J. Fósforo em solo e plantas em condições tropicais. Viçosa: UFV DPS, 1999. 399p.

12. PRADO, R.M., FERNANDES, F. M., ROQUE, C. G.. Resposta da cultura do milho a modos de aplicação e doses de fósforo, em adubação de manutenção. Revista Brasileira de Ciência do Solo, Viçosa, v.25 , n.1, p. 83-90, 2001.

13. RAIJ, B. V. Fertilidade do solo e adubação. Piracicaba: Editora S.A. 1991. 343p.

14. RIBEIRO, A.C.; GUIMARÃES, P. T. G.; ALVAREZ, V. H. Recomendação para uso de corretivos e fertilizantes em Minas Gerais ( $5^{\mathrm{a}}$ aproximação). Viçosa: UFV, 1999. 359p.

15. SÁ, J. C. M. Manejo da fertilidade do solo no plantio direto. Castro, Fundação ABC, 1993. 96p.

16. SÁ, J. C. M. Reciclagem dos resíduos culturais e estratégias de fertilização para produção de grãos no sistema plantio direto. In: Seminário sobre o sistema plantio direto na UFV. Universidade Federal de Viçosa. Departamento de Fitotecnia, 3 a 5 de abril de 1998, Anais... p 19-61, 1998. 143 p.

17. SCHULTZ, L. ARNO. Manual de plantio direto: técnicas e perspectivas. Porto Alegre: Agropecuária, 1978. 84p.

Recebido em 29/11/2002

Aceito em 20/02/2004 